\title{
Aprendizagem de professores sobre o conteúdo matemático e didático de números e operações
}

\author{
Vania Finholdt Angelo Leite ${ }^{1}$
}

\section{Resumo}

O estudo analisa as pesquisas produzidas por quatro grupos de pesquisas, verificando o que apontam sobre a aprendizagem dos professores que ensinam matemática. Utiliza o conceito de Comunidade de Prática como referencial teórico metodológico. As pesquisas apontaram que as professoras aprenderam sobre o conteúdo matemático de divisão e números fracionários. Em relação aos conteúdos didáticos os professores: a) permitiram aos alunos expressassem sua forma de pensar; b) (re) construíram sua forma de planejar; c) levantaram o conhecimento prévio dos alunos; d) integraram os eixos de conteúdos matemáticos e diversificaram as atividades em sala de aula.

Palavras-chave: Comunidade de Prática; Números e Operações; Formação de Professores; Ensino Fundamental I.

\section{Learning of teachers who teach mathematics about the mathematical and didactic content of numbers and} operations

\begin{abstract}
The study analyzes the researches produced by four research groups, verifying what they point out about the learning of teachers who teach mathematics. It uses the concept of Community of Practice as a methodological theoretical reference. The researches pointed out that the teachers learned about the mathematical content of division and fractional numbers. Regarding the didactic content, the teachers: a) allowed the students to express their way of thinking; b) (re) constructed their way of planning; c) raised the students' prior knowledge; d) integrated the axes of mathematical contents and diversified the activities in the classroom.

Keywords: Community of Practice; Numbers and Operations; Teacher training; Elementary School I.

\section{Aprendizagem de professores sobre el contenido matemático y didático de números y operaciones}

\section{Resumen}

El estudio analiza las investigaciones realizadas por cuatro grupos de investigación, verificando lo que señalan sobre el aprendizaje de los maestros que enseñan matemáticas. Utiliza el concepto de Comunidad de Práctica como referencia teórica metodológica. Las investigaciones señalaron que los maestros aprendieron sobre el contenido matemático de la división y los números fraccionarios. Respecto al contenido didáctico, los profesores: a) permitieron a los alumnos expresar su forma de pensar; b) (re) construyeron su forma de planear; c) elevar el conocimiento previo de los alumnos; d) Integrar los ejes de contenidos matemáticos y diversificar las actividades en el aula.

Palabras clave: Comunidad de Práctica; Números y Operaciones; Formación del profesorado; Escuela primaria I.
\end{abstract}

\section{Introdução}

Esse estudo concebe a aprendizagem docente como um fenômeno situado e construído socialmente. Isso significa que aprender não é só adquirir habilidades e informações, como

\footnotetext{
${ }^{1}$ Faculdade de Formação de Professores - São Gonçalo - Universidade do Estado do Rio de Janeiro (UERJ), vfaleite@uol.com.br
}

Periódico Horizontes - USF - Itatiba, SP - Brasil - e019044 
concebia a visão tradicional das ciências da cognição. Essas ciências estavam preocupadas com os comportamentos observáveis dos indivíduos e suas representações mentais.

Na teoria social, a aprendizagem é entendida como um aspecto integral e inseparável da prática social. Isso representa uma mudança na forma de analisar a aprendizagem, porque o foco está na interação, participação e nos significados construídos pelas pessoas quando participam de um grupo com interesses comuns. Assim, a ênfase é na pessoa, no seu envolvimento em um grupo, considerando cada indivíduo como ser por inteiro e não só com sua parte cognitiva.

Nesse texto, utilizo o conceito de Comunidade de Prática (CoP) proposto por Lave e Wenger (1991) a partir dos estudos que eles realizaram sobre aprendizagem baseando-se na Teoria Social e na Antropologia. Para os autores, as CoP podem ser definidas como grupos de pessoas que compartilham interesses comuns, cuja participação nesse grupo proporciona significado à experiência e, consequentemente, o seu aprendizado.

Pesquisar as formações continuadas a partir desse conceito, se distancia de concepções de treinamento, de atualização e de reciclagem, porque esses modelos estão ancorados em um padrão escolarizado, com organização em disciplinas, cursos e módulos. Muitas vezes, esse tipo de formação é apoiado na ideia de adquirir conhecimentos para aplicar em outra situação.

O conceito de CoP nos proporciona observar a aprendizagem dos docentes enquanto participantes de um grupo no qual eles desenvolvem e compartilham modo de fazer/ensinar e aprender, nesse caso, números e operações. Os professores se envolvem com questões que são relevantes para eles. Não é uma proposta de fora e/ou impostas por outros, mas é construída pela (re) negociação constante entre os membros da comunidade.

Este texto analisa oito pesquisas sobre números e operações publicadas a partir de 2013, do grupo de Ana Maria Abrahão, Ana Teresa Oliveira, Maria Auxiliadora Paiva e Sandra Aparecida Silva. A seleção desses grupos ocorreu, porque eles coordenaram o levantamento do Estado do Rio de Janeiro e Espírito Santo que compõem o "Mapeamento de pesquisa acadêmica brasileira sobre professor que ensina Matemática: período 2001-2012" (FIORENTINI; PASSOS; LIMA, 2016). O interesse em fazer esse levantamento se deve ao fato da autora desse artigo, pesquisar sobre os professores que ensinam matemática nos anos iniciais. É relevante que saibamos o que outros grupos estão produzindo a esse respeito.

Periódico Horizontes - USF - Itatiba, SP - Brasil - e019044 
Este artigo tem como corpus de análise as oito pesquisas selecionadas a partir destes quatro grupos de pesquisas fluminenses e capixabas, buscando verificar o que apontam sobre a aprendizagem dos professores que ensinam matemática (PEM) durante a formação continuada nos anos iniciais do Ensino Fundamental I sobre números e operações. Busquei os artigos publicados a partir de 2013, porque não constam no mapeamento citado anteriormente. Selecionei os artigos de eventos, das dissertações e das teses sobre PEM nos anos iniciais sobre números e operações desses quatro grupos de pesquisa.

Nesse mapeamento, as pesquisadoras Oliveira, Abrahão, Paiva, Silva (2016) apontaram uma carência de estudos que se aprofundem na temática do professor que ensina matemática (PEM) nos anos iniciais. Para as pesquisadoras, "trata-se de um campo ainda carente de estudos que se dediquem à formação e à prática do docente para ensinar Matemática nessas etapas da formação dos alunos" (OLIVEIRA, ABRAHÃO, PAIVA, SILVA, 2016, p. 249). O estudo delas corrobora com um estudo anterior de Gatti e Barreto (2009). Por isso, se justifica um estudo como esse, que se propõe realizar um levantamento a partir de 2013, analisando as formações continuadas de PEM, porque é fundamental que possamos entender o que favorece ou não a aprendizagem dos professores em relação aos conteúdos matemáticos e a didática desses conteúdos matemáticos, quando participam de formação continuada.

Outro motivo é o fato da matemática ser uma área 'temida' por alguns professores, o que os levam a optarem pelo Curso de Pedagogia para não ter que lidar com ela. De fato, os alunos do Curso de Pedagogia não têm oportunidade de aprofundarem nas questões de matemática, uma vez que a carga horária da disciplina é pequena, como corrobora Curi e Pires (2008); Costa; Pinheiro e Costa (2016, p. 505), elas apontam que "existe um número expressivo de cursos que contemplam uma carga horária reduzida na formação matemática". Esse estudo só abrange o eixo de números e operações, o que pode ser considerado uma limitação. Não foram incluídos os outros eixos, como o de espaço e forma, porque requer outro tipo de pensamento, de descrição e representação, diferentes do eixo selecionado. Outro limite é o tamanho do corpus de análise, que não permite uma generalização, mas, por outro lado, fornece indícios para pensar sobre o planejamento de futuras formações continuadas.

Diante do exposto, apresento as seguintes questões norteadoras: o que os grupos de Periódico Horizontes - USF - Itatiba, SP - Brasil - e019044 
pesquisa coordenados por essas pesquisadoras produziram sobre PEM no Ensino Fundamental (1 ao 5 ano) na formação continuada de professores sobre números e operações a partir de 2013? Quais são os saberes construídos pelos PEM durante as formações continuadas? O que proporcionou essa construção?

Reafirmo que para análise das pesquisas selecionadas, utilizo o conceito de Comunidade de Prática (LAVE; WENGER, 1991), porque compreendo que a aprendizagem dos professores ocorre pelo engajamento em atividades desenvolvidas em uma comunidade pelo fato de as relações constituírem fontes geradoras de aprendizagem.

\section{Comunidade de Prática: contribuições de Lave e Wenger}

$\mathrm{Na}$ teoria social de aprendizagem, as comunidades se caracterizam por atividades e práticas específicas que definem os limites de pertencimento e identidade delas. Nas palavras de Wenger, a comunidade de prática (CoP) é formada por "grupos de pessoas que compartilham uma preocupação ou uma paixão por algo que eles fazem e aprendem como fazê-lo melhor quando eles interagem regularmente" (WENGER, 2015, p. 1). Isso significa que se trata de pessoas que possuem os mesmos interesses, compartilham competências em determinado assunto e estabelecem uma prática. Prática aqui não é usada como dicotômica entre ação e conhecimento, saber e fazer, manual e mental. Para Wenger (1998), a prática inclui o repertório compartilhado de recursos de uma comunidade, ou seja, a linguagem, as ferramentas, os contratos, as regras, os símbolos, as formas de se resolverem problemas de uma comunidade. Ao afiliar-se a um grupo de trabalho, independente de esse grupo ser ou não organizado com o propósito de ensinar algo, as pessoas constituintes dele aprendem pelo fato de participar ativamente das práticas dessa comunidade. No caso dessa pesquisa, o fato dos professores participarem de grupos de estudo ou formação continuada em uma escola poderá se constituir uma comunidade de prática, se contemplarem as três dimensões apontadas por Wenger (1998).

A primeira se refere ao engajamento mútuo dos participantes. Para que ocorra é necessário que os participantes interajam enquanto realizam uma tarefa em conjunto. Essa interação pode ocorrer presencialmente ou não. O que torna o engajamento possível é a 
diversidade das competências de cada membro, o que cada um sabe, o que faz, bem como a habilidade que possui para conectar-se ao que não sabe e não faz, complementando os conhecimentos e as ações dos demais membros.

A segunda dimensão é o empreendimento conjunto definido pelos participantes no processo de constituição de uma CoP, mas é (re)negociado constantemente pelos membros, não é um acordo estático. A confiança e o respeito estabelecidos entre os membros da CoP são fundamentais para a realização do trabalho conjunto e as trocas de informações. A comunidade está sempre negociando seu empreendimento, e as influências externas não teriam poder direto sobre a comunidade. Para que o empreendimento seja coletivo, é necessário que as pessoas compreendam que fazem parte do todo e sintam-se responsáveis em relação às suas tarefas. Mas, não significa que elas têm que concordar com tudo o tempo todo.

A terceira se refere ao repertório compartilhado de discurso e ação criados pelo empreendimento conjunto que a comunidade constrói com o passar do tempo juntos. $\mathrm{O}$ repertório pode incluir as palavras, as ferramentas, as formas de realizar tarefas, histórias, gestos, símbolos, ações ou conceitos que a comunidade criou ou adotou durante a sua existência.

A comunidade se difere de uma entidade institucional porque em uma CoP, os membros negociam seu próprio empreendimento, podem dissolver o acordo e os encontros entre eles e moldam suas próprias fronteiras. Uma comunidade não se resume a uma reunião de pessoas ou grupos, é necessário que objetivos e tarefas sejam negociados pelos seus membros que se engajam para lidarem com as dificuldades e as inquietações decorrentes da prática. (WENGER, 1998).

\section{Caminhos metodológicos}

O corpus de análise foi construído após acessar o currículo lattes de cada pesquisadora Oliveira; Abrahão; Paiva; Silva (2016). Listei todos os artigos publicados em periódicos, eventos, as participações em bancas de dissertações e teses nos Estados do Rio de Janeiro e Espírito Santo a partir de 2013. Em seguida, acessei os estudos disponíveis na internet para lê-los integralmente. Tive dificuldade de encontrar todos os selecionados para serem analisados, como por exemplo, duas dissertações não estão disponíveis no site da Universidade. Por isso, só 
constam as pesquisas que puderam ser acessadas e lidas integralmente.

Após a leitura do resumo das vinte e cinco pesquisas selecionadas, foram excluídas aquelas que não abordavam o tema números e operações. O motivo de escolher esse eixo para análise se deve ao fato de ser o conteúdo mais recorrente nas atividades de sala de aula, em livros didáticos e, consequentemente, espera-se que as professoras do Ensino Fundamental I tivessem maior conhecimento prévio deles. Além disso, foram retiradas as de formação inicial de professores do Curso de Pedagogia ou licenciatura em Matemática, Educação de Jovens e Adultos e educação inclusiva.

Apresento, a seguir, um quadro dos oito estudos que fizeram parte do corpus de análise desse texto:

Quadro 1. Síntese do corpus de análise

\begin{tabular}{|c|c|c|}
\hline Autores & $\begin{array}{l}\text { Objetivo } \\
\text { (continua) }\end{array}$ & $\begin{array}{c}\text { Tipo de } \\
\text { publicação }\end{array}$ \\
\hline $\begin{array}{l}\text { BAZET, Lydia Marcia Braga } \\
\text { (2014) }\end{array}$ & $\begin{array}{c}\text { Analisa a narrativa e reflexão de } 5 \text { professores dos anos iniciais } \\
\text { e educação infantil a partir da participação no Grupo de } \\
\text { Estudos de Educação Matemática (GEEM-ES) nas discussões } \\
\text { sobre ensino e aprendizagem de divisão. }\end{array}$ & $\begin{array}{l}\text { Dissertação } \\
\text { Mestrado } \\
\text { Profissional } \\
\text { (MP) }\end{array}$ \\
\hline $\begin{array}{l}\text { SESSA, Simone de Melo } \\
\text { (2014) }\end{array}$ & $\begin{array}{c}\text { Analisa o processo dialógico, reflexivo e as ações colaborativas } \\
\text { ocorridas em um grupo de estudos sobre ensino e } \\
\text { aprendizagem de matemática. }\end{array}$ & $\begin{array}{l}\text { Dissertação } \\
\qquad(\mathrm{MP})\end{array}$ \\
\hline Autores & $\begin{array}{c}\text { Objetivo } \\
\text { (conclusão) }\end{array}$ & $\begin{array}{c}\text { Tipo de } \\
\text { publicação }\end{array}$ \\
\hline $\begin{array}{l}\text { ABRAHÃO, Ana Maria } \\
\text { Carneiro (2016) }\end{array}$ & $\begin{array}{c}\text { Aborda a reflexão do significado de número racional e o } \\
\text { entendimento de suas diferentes formas de representação } \\
\text { para alunas do Curso de Pedagogia }\end{array}$ & Artigo \\
\hline $\begin{array}{c}\text { ABRAHÃO, Ana Maria } \\
\text { Carneiro; NAMAN, Lúcia; } \\
\text { SPINOLA, Marcela da Silva } \\
\text { (2016) } \\
\end{array}$ & $\begin{array}{l}\text { Pesquisa bibliográfica que analisa os trabalhos científicos } \\
\text { publicados pela Escola de Educação da UNIRIO entre } 2012 \text { e } \\
2016 \text { voltadas para estudo de professores que ensinam } \\
\text { matemática. }\end{array}$ & Artigo \\
\hline $\begin{array}{l}\text { LOPES, Aparecida Ferreira } \\
\text { (2016) }\end{array}$ & $\begin{array}{l}\text { Analisa o processo de formação de professores em } \\
\text { (re)construção do conhecimento de frações e seus diferentes } \\
\text { significados por professores dos anos iniciais. }\end{array}$ & Artigo \\
\hline $\begin{array}{l}\text { GAIGHER, Vanessa Ribeiro } \\
\text { (2017) }\end{array}$ & $\begin{array}{l}\text { Analisa as contribuições das ações colaborativas e reflexivas na } \\
\text { formação de professores em aulas de resolução de problemas. }\end{array}$ & $\begin{array}{l}\text { Dissertação } \\
\text { (MP) }\end{array}$ \\
\hline $\begin{array}{l}\text { LOPES, Aparecida Ferreira; } \\
\text { COCO, Dilza; SILVA, Sandra } \\
\text { Aparecida Fraga (2017) }\end{array}$ & $\begin{array}{l}\text { Analisa a formação continuada com professores dos anos } \\
\text { iniciais sobre diferentes significados de frações. }\end{array}$ & Artigo \\
\hline $\begin{array}{l}\text { SILVA, Sandra Aparecida } \\
\text { Fraga da; Côco, Dilza } \\
\text { (2017) }\end{array}$ & $\begin{array}{l}\text { O artigo analisa três formações de professores, buscando } \\
\text { verificar as apropriações e práticas de professores em relação } \\
\text { aos conhecimentos matemáticos. }\end{array}$ & Artigo \\
\hline
\end{tabular}

Fonte: a autora. 
Trago a seguir, uma descrição de cada pesquisa selecionada:

A pesquisa de Bazet (2014) analisa a aprendizagem de 5 (cinco) professoras de Educação Infantil e Anos iniciais do Ensino Fundamental que participam do Grupo de Estudos de Educação Matemática (GEEM-ES). A principal fonte de dados da pesquisadora foram as narrativas e as reflexões dessas professoras em relação a divisão. De acordo com Bazet (2014, p.10), o grupo de estudos ocorre semanalmente, é um espaço "para discutir, compartilhar experiências e instigar mudanças de atitudes e procedimentos em sala de aula, a partir de pesquisa e reflexões sobre situações vivenciadas em suas práticas pedagógicas docentes".

Sessa (2014) examina a repercussão no processo formativo de seis integrantes de um grupo de estudos sobre ensino e aprendizagem de matemática. Sendo 4 (quatro) professoras dos anos iniciais, a diretora e a pesquisadora. Na investigação utilizou-se dos seguintes instrumentos para coletar os dados: anotações das professoras (relatos de intervenções pedagógicas na sala de aula), gravações de áudio, vídeo e fotografias. Sessa (2014, p.53) destaca que "a participação no grupo foi voluntária".

Abrahão (2016) reflete sobre o significado do número racional e as diferentes formas de representações desses números em atividades investigativas desenvolvidas com alunas do Curso de Pedagogia. Abrahão (2016, p. 700) afirma que "ao dar voz aos participantes para expor suas dúvidas, questionar e argumentar a escolha de seus caminhos abre-se possibilidades para que eles também desenvolvam o hábito de escutar seus alunos e analisar suas argumentações".

Abrahão; Naman; Spinola (2016) fazem um mapeamento de trabalhos sobre formação de professor que ensina matemática nos anos iniciais e na Educação Infantil realizados na Universidade Federal do Estado do Rio de Janeiro (UNIRIO) no período de 2012 a 2016. Evidenciou-se que nos programas de pós-graduação não se pesquisam sobre essa temática. As pesquisadoras encontraram monografias do Curso de Pedagogia e projetos de pesquisas com essa temática na UNIRIO.

Lopes (2016) apresenta no seu artigo uma revisão bibliográfica sobre o tema formação de professores e o processo de ensino e aprendizagem de frações de professores dos anos iniciais. Além disso, a pesquisadora analisa um questionário realizado com 9 (nove) professoras do ensino fundamental da rede municipal de Vila Velha e Vitória sobre essa temática. 
Gaigher (2017) investigou as contribuições de ações colaborativas e reflexivas na formação de professores de matemática em aulas de resolução de problemas. Participaram da pesquisa 9 (nove) alunos-professores de Matemática. Eles são docentes do ensino básico e mestrandos do Programa de Pós-graduação em Educação em Ciências e Matemática do Instituto Federal do Espírito Santo.

Lopes; Côco; Silva (2017) apresentam os dados de pesquisa coletados em 7 (sete) encontros de formação continuada com professores dos anos iniciais sobre o tema diferentes significados de frações. De acordo com as autoras (2017, p. 1), a pesquisa evidenciou que "é importante pensar a formação numa perspectiva dialógica e coletiva, onde situações-problema articulam diferentes conhecimentos que podem ser abordados no significado de fração partetodo".

Silva e Côco (2017) discutem nesse artigo os dados coletados em três cursos de extensão realizados entre 2015 e 2016 no Instituto Federal do Espírito Santo - Campus Vitória. Para esse texto, selecionei a análise do terceiro curso sobre frações e seus significados destinado a educadores dos anos iniciais. As pesquisadoras apontam que as formações possibilitaram "promover o desenvolvimento profissional do professor numa dimensão coletiva, dialógica, onde a apropriação de conhecimentos possibilita uma nova qualidade para as ações de ensino dos participantes" (SILVA; CÔCO, 2017, p.68).

Observamos que todas as pesquisas e artigos analisados são qualitativos e de mestrado profissional. Os conteúdos abordados do eixo de números e operações são os seguintes: divisão, números racionais, fração e seus significados. Das oito pesquisas, percebe-se que seis pesquisas, aqui relacionadas: Bazet (2014); Sessa (2014); Abrahão (2016); Gaigher (2017); Lopes; Coco; Silva, (2017) e Silva; Côco (2017), apontam indícios de que a formação proporcionou um espaço no qual os participantes puderam discutir, compartilhar experiências, expor suas dúvidas durante as atividades. Enquanto que as pesquisas de Abrahão; Naman; Spinola (2016) e Lopes (2016) mapeiam as pesquisas de formação de professores que ensinam matemática nos anos iniciais. São, portanto, bibliográficas.

Todas essas pesquisas abordam sobre a temática formação de professores e temas ligados a números e operações. No entanto, nenhuma delas utilizou o referencial da teoria social 
da aprendizagem. Foi a autora desse texto que fez as análises dessas pesquisas tendo por base essa teoria.

\section{Análise dos dados}

Como mencionei anteriormente, analisei as pesquisas apontadas no item anterior. Por isso, todos os dados apresentados a seguir são oriundos delas. A partir do referencial de Lave e Wenger (1998), examinei o corpus tendo as seguintes categorias: 1) engajamento mútuo; 2) empreendimento conjunto; 3) repertório compartilhado.

Em uma CoP os membros têm diferentes interesses, contribuem de maneira diversa com a atividade e apresentam variados pontos de vista. No entanto, o que os unem (o engajamento mútuo) é a prática que eles têm em comum. Nesse caso, ensinar matemática nos anos iniciais. As professoras que participaram das seis pesquisas (mencionadas anteriormente) buscaram a formação para discutir temas, como a de divisão, número racional e representações fracionárias, significado de fração parte-todo, porque elas sentiam necessidade de aprofundar e aprender um pouco mais sobre eles. Um depoimento, expressa essa intenção: "eu quis participar do grupo para aperfeiçoar a minha prática de aula e para uma troca de experiências com as colegas" (SESSA, 2014, p.96). Mesmo que tivessem mais de uma escola para trabalhar, elas valorizavam a aprendizagem que construíam juntas nos encontros que realizavam. Isso denota o quanto a formação contribui para que as professoras saíssem do isolamento da sua sala de aula para compartilhar com outras docentes suas experiências, dúvidas e produções.

O engajamento mútuo ocorreu porque as docentes tinham o desejo de participar de um grupo/formação que the propiciasse um melhor entendimento dos conteúdos matemáticos. Evidenciado por Silva e Côco $(2017$, p.85), elas afirmam que "as discussões foram motivadas por um motivo pessoal que as professoras trouxeram de sua docência, de seu trabalho e que se transformou em um motivo coletivo compartilhado pelos envolvidos". Assim como menciona outra professora: "eu aceito fazer parte do grupo porque experiência a gente tem muita, mas tempo para estudar e compartilhar as coisas com as colegas nós temos pouco" (SESSA, 2014, p.63).

Periódico Horizontes - USF - Itatiba, SP - Brasil - e019044 
A escolha do conteúdo que seria discutido e refletido era selecionado e compartilhado entre as professoras. As tarefas conjuntas envolviam estudo de texto sobre o tema da formação, relato de experiência dos professores, análise de atividades de crianças trazidas pelos professores e propostas pela formadora e atividades dos erros dos alunos. Não era a Secretaria de educação que decidia e impunha o conteúdo da formação.

Outra característica do engajamento mútuo é a diversidade de competência dos participantes da comunidade. A diversidade de habilidades estava presente nas formações descritas na pesquisa de Gaigher (2017, p.55). Ela menciona que as discussões contribuíram "com a diversidade de olhares, experiência e sugestões para que a aula tivesse o melhor design, além de fornecer um maior suporte, aos alunos-professores, para o que poderia ocorrer em aula". Considero que as professoras perceberam que ao participar dessas formações, elas aprendiam sobre os conteúdos números e operações e davam sentido as suas experiências de sala de aula. Como aponta uma professora da pesquisa de Bazet (2014, p.66) "no trabalho com a divisão, as discussões favoreceram a uma compreensão mais adequada de ensinar aos alunos valorizando suas estratégias e ampliando outras possibilidades de resolução".

Em relação ao empreendimento conjunto, que emerge da negociação coletiva dos membros. É a segunda característica de uma comunidade de prática. Envolve iniciativas dos participantes que incluem aspectos instrumentais, pessoais e interpessoais, de forma conjugada, num processo de produção coletiva de um produto que resulta dessa negociação. Todas estavam engajadas para aprender e aprofundar seus conhecimentos a respeito de um conteúdo matemático. O produto desse engajamento seria uma prática de ensinar que favorecesse a aprendizagem de seus alunos. Para isso, era necessário o respeito e confiança entre elas, porque todo processo de aprendizagem requer, erros e acertos.

As seis pesquisas apontaram que durante a formação houve respeito e confiança para que as professoras expusessem suas dúvidas, aflições, decepções ou sucessos, como evidencia Sessa (2014, p. 73): "as professoras demonstram necessidade de compartilhar suas angústias, aflições, decepções ou sucessos". [..] Isso contribui para o sucesso do grupo, para a continuidade do mesmo. [...] sem temer julgamentos, as parceiras buscaram o apoio umas nas outras". As professoras demonstraram coragem para falar de suas dúvidas e não saberes matemáticos, 
porque tiveram o grupo para Ihes apoiar. O grupo se constituiu como um espaço em que elas puderam compartilhar suas dificuldades e suas potencialidades. Isso favoreceu aprendizagens das professoras, como mencionam as professoras das pesquisas analisadas:

a divisão faz parte de um campo de conceitos e procedimentos que devem ser trabalhados de forma contextualizada e a partir da compreensão do aluno. 0 papel do professor é mediar essa compreensão para que o aluno faça a ponte entre os conceitos espontâneos e o conceito científico (BAZET, 2014, p.62).

[...] Hoje, ensinar divisão é criar caminhos diferentes para resolver a mesma situação. Valorizar as estratégias de cálculo seja com representações icônicas ou simbólicas até formalizar o algoritmo (BAZET, 2014, p.67).

Vou um pouco mais ao laboratório de informática e sempre que necessário uso jogos e tenho visto novas estratégias para melhorar a aprendizagem dos meus alunos (SESSA, 2014, p.100).

Percebemos nesses três depoimentos que as professoras aprenderam sobre o conteúdo matemático, nesse exemplo, o da divisão, assim como, os aspectos didáticos ligados a ele. As professoras apontaram que se preocupam com a intervenção que fariam para que os alunos pudessem aprender. Incluindo nessa mediação a valorização das estratégias, os jogos e as representações icônicas ou simbólicas. As formações, portanto, contribuíram para que essas professoras aprimorassem sua prática pedagógica, como evidencia a pesquisa de Gaigher (2017, p. 97) "por meio das experiências compartilhadas, o aluno-professor foi incentivado a aprender novos conceitos, metodologias e promover práticas que não poderiam ser programadas em situações que o professor estaria planejando individualmente".

Outra aprendizagem das professoras se refere ao planejamento de suas aulas. Lopes, Côco e Silva $(2017$, p.9) indicam que as professoras passaram a analisar os enunciados das situaçõesproblema: "Contudo, chamo atenção para a formulação de alguns enunciados que deram margem para dúvidas ou respostas duplicadas (mais de uma possibilidade)". Assim, como, pensar em atividades que desafiassem os alunos a pensar em diferentes representações de um inteiro (representação fracionária). Na pesquisa de Silva e Côco (2017, p.85), uma das professoras menciona que "após planejamentos, resolvemos iniciar com os alunos a ideia do todo e para que 
os alunos entendessem o que é o todo, levei para a sala pães em diversos formatos [...], garrafa com água, papel higiênico, um pote de lápis de cor e uma caixa de bombom".

Portanto, o empreendimento conjunto nessas pesquisas foi o de se apropriar de conhecimentos matemáticos e didáticos de um determinado conteúdo e o conceito envolvido nele. Com essa aprendizagem, "[...] por meio das discussões feitas pelo grupo, forneceram elementos que deixavam o professor que iria executar a aula mais seguro do que e do como propor alguma prática em sala de aula" (GAIGHER, 2017, p.80).

Em relação ao repertório compartilhado, todas as professoras participantes eram professoras polivalentes dos anos iniciais, em sua maioria com formação em Pedagogia. Concluise, portanto, que compartilham linguagens, ferramentas e formas de atuar da comunidade de professores. No entanto, ainda não se apropriaram da "linguagem matemática e alguns símbolos matemáticos" (GAIGHER, 2017, p. 156), e estão aprendendo alguns conceitos, como por exemplo, parte-todo e inteiro (SILVA et al, 2017). Essas aprendizagens foram construídas durante a formação, como evidencia o trecho: "eu compreendi quase quinze anos lecionando que uma rosca com um furo no meio é inteira. Ela continua sendo inteira, mas até agorinha eu achava que ela estava faltando uma parte" (SILVA; CÔCO, 2017 p.83). Esse depoimento ilustra/mostra como as professoras foram ressignificando os conceitos trabalhados na formação. Nesse exemplo, o conceito de inteiro. Isso ocorreu porque elas tiveram espaço para expor suas dúvidas o que denota uma confiança entre elas, puderam pensar junto com as colegas e a formadora. $\mathrm{Na}$ interação com os colegas, houve uma negociação de significado sobre o conceito de inteiro, como no citado anteriormente.

Portanto, percebe-se que o engajamento mútuo e o empreendimento conjunto das professoras durante as formações continuadas proporcionaram a construção de saberes referentes alguns conteúdos matemáticos e a como ensiná-los, apontados a seguir. Esses saberes foram identificados após a análise das pesquisas descritas anteriormente.

Em relação à aprendizagem do conteúdo matemático de números racionais e suas representações, as pesquisas de Bazet (2014), Abrahão (2016), Lopes; Côco; Silva (2017) e Silva; Côco (2017) apontam que as professoras se apropriaram do significado de inteiro, parte e todo, ideia de partição, cota, proporção e diferentes formas de pensar/representar frações. 
Quadro 2. Síntese da aprendizagem de conteúdo matemático e dos conhecimentos didáticos

\begin{tabular}{|c|c|c|c|}
\hline Autores & Conteúdo & $\begin{array}{c}\text { Aprendizagem do conteúdo } \\
\text { matemático }\end{array}$ & $\begin{array}{c}\text { Conhecimentos didáticos } \\
\text { (continua) }\end{array}$ \\
\hline Bazet (2014) & Divisão & $\begin{array}{c}\text { “Valorizar as estratégias de } \\
\text { cálculo" (p.67). } \\
\text { “A divisão engloba várias ideias } \\
\text { como cotas, partição e proporção, } \\
\text { além das naturezas contínua e } \\
\text { discreta” (p. 67). }\end{array}$ & $\begin{array}{c}\text { “Abordo situações } \\
\text { envolvendo a divisão sem que } \\
\text { necessariamente tenha que } \\
\text { falar qual é a operação ou } \\
\text { apresentar o algoritmo; } \\
\text { entendi melhor as ideias da } \\
\text { divisão e como posso fazê-las } \\
\text { significativas em sala na } \\
\text { aprendizagem dos alunos" } \\
\text { (p.59). } \\
\text { "preocupo-me mais ao } \\
\text { planejar as aulas em propor } \\
\text { ao aluno diferente formas } \\
\text { para que ele perceba como } \\
\text { funciona o processo de } \\
\text { divisão" (p.60). } \\
\text { “ensinar aos alunos } \\
\text { valorizando suas estratégias" } \\
\text { (p.66). }\end{array}$ \\
\hline Abrão (2016) & $\begin{array}{l}\text { Números } \\
\text { racional e formas } \\
\text { de } \\
\text { representação }\end{array}$ & $\begin{array}{l}\text { Localizar uma fração própria em } \\
\text { uma reta numérica (p.688). } \\
\text { Representar frações impróprias e } \\
\text { compreender que nem sempre “a } \\
\text { fração é uma parte menor do que } \\
\text { um inteiro” (p. 690). }\end{array}$ & $\begin{array}{l}\text { [os professores] "envolvidos no } \\
\text { estudo têm a oportunidade de } \\
\text { rever sua prática pedagógica e } \\
\text { aperfeiçoar o seu fazer } \\
\text { profissional” (p.700). }\end{array}$ \\
\hline Autores & Conteúdo & $\begin{array}{c}\text { Aprendizagem do conteúdo } \\
\text { matemático }\end{array}$ & $\begin{array}{c}\text { Conhecimentos didáticos } \\
\text { (conclusão) }\end{array}$ \\
\hline $\begin{array}{c}\text { Lopes;Côco;Silva } \\
\text { (2017) }\end{array}$ & $\begin{array}{l}\text { Problemas de } \\
\text { divisão }\end{array}$ & $\begin{array}{l}\text { "Problemas que podiam ser } \\
\text { resolvidos com números naturais e } \\
\text { os que só poderiam ser resolvidos } \\
\text { com números fracionários" (p.9). }\end{array}$ & $\begin{array}{c}\text { “as professoras começaram a } \\
\text { pensar na característica dos } \\
\text { conjuntos (contínuo e } \\
\text { discreto)" para propor desafios } \\
\text { aos alunos (p.4). } \\
\text { As docentes passaram se } \\
\text { preocupar com a "elaboração } \\
\text { do enunciado" (p.9). }\end{array}$ \\
\hline Silva; Côco (2017) & $\begin{array}{l}\text { Frações e seus } \\
\text { significados }\end{array}$ & $\begin{array}{l}\text { "Representação de um inteiro - o } \\
\text { todo - com figuras não usuais" } \\
\text { (p.83). }\end{array}$ & $\begin{array}{l}\text { “indo e vindo com as } \\
\text { anotações e desenhos no } \\
\text { quadro os alunos foram } \\
\text { entendendo não só o conceito } \\
\text { de inteiro, mas também o que } \\
\text { representa o numerador; o } \\
\text { denominador; frações } \\
\text { equivalentes, parte-todo, } \\
\text { além do conceito de divisão e } \\
\text { medida” (p.85). }\end{array}$ \\
\hline
\end{tabular}

Fonte: Elaborado pela autora 
Quanto aos conhecimentos didáticos relacionados a esses conteúdos, podemos enumerar os seguintes, a partir dos exemplos do quadro II: a) as professoras passaram a incentivar as estratégias pessoais dos alunos na solução de problemas com divisão, solicitar que os alunos as explicassem, explorar os conhecimentos prévios dos alunos e diferentes formas de desenvolver o raciocínio da divisão (BAZET, 2014); b) as professoras se familiarizaram com materiais concretos e recursos diversos para ensinar números fracionários; deixaram que as crianças apresentassem suas ideias, dúvidas e propostas (ABRAHÃO, 2016); c) as docentes incentivavam as diferentes formas de elaborar o cálculo mental em sala de aula; proporcionavam que os alunos elaborassem estratégias pessoais. Elas elaboraram um planejamento com situações-problema desafiadoras para as crianças evidenciado por Lopes; Côco e Silva (2017) e Silva e Côco (2017).

Quanto a aprendizagem dos conteúdos de sistema de numeração decimal, Sessa (2014), Gaiher (2017) observaram as seguintes aprendizagens de operações e situações-problema.

Quadro 3. Síntese da aprendizagem do conteúdo matemático e dos conhecimentos didáticos

\begin{tabular}{|c|c|c|c|}
\hline Autores & Conteúdo & $\begin{array}{l}\text { Aprendizagem do conteúdo } \\
\text { matemático }\end{array}$ & Conhecimento didático \\
\hline Sessa (2014) & $\begin{array}{l}\text { Ideias de } \\
\text { multiplicação } \\
\text { Subtração } \\
\text { Situações- } \\
\text { problema } \\
\text { Divisão } \\
\text { Tratamento da } \\
\text { informação }\end{array}$ & $\begin{array}{l}\text { Configuração retangular; } \\
\text { Combinatória; } \\
\text { Ler e interpretar dados em } \\
\text { tabelas e gráficos; }\end{array}$ & $\begin{array}{l}\text { "não tem mais isso de dividir os } \\
\text { conteúdos nos trimestres, esse } \\
\text { trimestre isso, aquele trimestre } \\
\text { aquilo." (p.100). } \\
\text { Diferentes estratégias para trabalhar } \\
\text { com o conteúdo, por exemplo: jogo, } \\
\text { reta numérica, dobraduras, tangran. }\end{array}$ \\
\hline Gaiher (2017) & $\begin{array}{l}\text { Resolução de } \\
\text { problemas }\end{array}$ & $\begin{array}{l}\text { "Diversidade de estratégia para } \\
\text { resolução de problemas" (p.68). } \\
\text { "compreensão do problema e } \\
\text { estabelecimento de estratégia } \\
\text { de resolução “ (p.71). }\end{array}$ & $\begin{array}{l}\text { “os questionamentos ajudaram a } \\
\text { encontrar o ponto de partida e a } \\
\text { refletir sobre as estratégias [...]” (p.71). } \\
\text { “valorizava as respostas e dúvidas dos } \\
\text { alunos, para que continuassem suas } \\
\text { tentativas [...]" (p.75). } \\
\text { “criar oportunidades de diálogos e } \\
\text { desenvolver a confiança dos alunos em } \\
\text { justificar matematicamente suas } \\
\text { estratégias" (p.82). } \\
\text { “a utilização do erro do aluno como } \\
\text { elemento para a construção conjunta } \\
\text { da resolução" (p.129). }\end{array}$ \\
\hline
\end{tabular}

Fonte: Elaborado pela autora

Em relação à aprendizagem dos conhecimentos didáticos desses conteúdos, como aponta Periódico Horizontes - USF - Itatiba, SP - Brasil - e019044 
os trechos acima, Sessa (2014) indica que as professoras passaram a usar após a formação, mais jogos em sala de aula, trabalhavam com os blocos de conteúdos matemático de forma integrada, abordavam a matemática relacionando-a ao cotidiano, minimizando o problema da indisciplina. Gaigher (2017) observou que as professoras planejavam aulas se preocupando com o enunciado das situações-problema, se elas estavam ou não desafiadoras. Incentivavam os alunos a usar diferentes estratégias, compartilhar suas soluções e compreender as dos outros.

\section{Considerações finais}

O referencial teórico-metodológico de Comunidade de Prática (CoP) se mostrou potente para que possamos compreender o processo de aprendizagem docente durante a formação continuada descritas nas pesquisas. No caso deste estudo, essas pesquisas não se denominavam CoP, mas apresentavam duas dimensões apontadas por Wenger e Lave (1998) que são o engajamento mútuo e o empreendimento conjunto. Essas duas dimensões foram fundamentais para o processo de aprendizagem das professoras. Primeiro, demonstra que a vontade e o desejo das professoras em participar de um grupo/formação com discussões de temas matemáticos são fatores essenciais no processo de aprendizagem.

Essa revisão demonstra que quando o professor tem oportunidade de participar voluntariamente de formação com características de uma CoP, que faz sentido ao seu fazer diário em sala de aula, ele se engaja nas atividades motivado pelo interesse de aprender, ser ouvido, respeitado e contar com parceiros para discutir suas experiências, angústias e (in)sucessos. Participa dessa formação porque ele percebe que os participantes possuem diferentes habilidades e conhecimentos que vão se completando e possibilitando a aprendizagem de todos.

Outro fator é o compartilhamento de saberes e não saberes em relação aos temas. Isso foi possível porque havia um respeito e confiança entre os participantes, como também, souberam aproveitar a diversidade de saberes/conhecimentos para que todos pudessem aprender juntas. Todos os participantes dos grupos/formações se tornaram mais confiantes e seguros para rever sua prática e discutir com os colegas, porque estavam aprendendo juntos sobre o conteúdo matemática e sua didática.

Periódico Horizontes - USF - Itatiba, SP - Brasil - e019044 
Essas formações consideram as práticas e os saberes mobilizados e construídos pelos docentes em seu cotidiano, tornando-os objeto de estudo e problematização. Assim, corrobora com afirmativa de Wenger (2001, p.20), que a "a aquisição de conhecimento não é uma simples questão de absorver conhecimento". No entanto, no contexto educativo atual no Brasil, as políticas educativas têm propostas bem diferentes de formação das elencadas nesse estudo. As políticas têm cerceado o fazer docente e sua formação, na maioria das vezes, eles precisam seguir metas e materiais didáticos padronizados, tirando sua autonomia na sala de aula. As formações são transmissivas e buscam "moldar" uma forma de ensinar que foca na repetição de determinados conteúdos pelos alunos que serão verificados em testes padronizados.

Uma formação na perspectiva de uma CoP nos auxilia a pensar em como organizar/planejar formações continuadas que favoreçam o processo de aprendizagem de conteúdos matemáticos e os respectivos conhecimentos didáticos.

Em relação à aprendizagem dos conteúdos didáticos construídos pelos professores, foram subdivididos em dois grupos:

a) os professores permitiram que os alunos expressassem sua forma de pensar, socializando com os seus colegas. Os professores, solicitaram então, que os alunos explicitassem as estratégias pessoais, que eles explicassem como haviam pensado e elaborado diferentes formas de resolver uma situação/cálculo. Ao permitirem que os alunos utilizassem essas estratégias, os professores favoreceram que os alunos desenvolvessem autonomia e confiança na sua forma de pensar matematicamente. Os alunos não serão aqueles que esperarão do adulto uma solução mais adequada para determinada situação, não estarão apegados a uma única forma de resolver uma situação problema.

b) os professores (re) construíram sua forma de planejar a aula. Eles passaram a levantar o conhecimento prévio dos alunos, buscaram integrar os eixos de conteúdos matemáticos e diversificaram as atividades em sala de aula, como por exemplo, os jogos. Assim, o planejamento de aula não era burocrático, mas estava de acordo com as necessidades de seus alunos. Nas palavras de Freire (1997), os professores não separaram o conteúdo a ser ensinado, do sujeito (partiam dos conhecimentos prévios 
deles) e da classe de alunos (diversificaram as atividades). Dessa forma, os alunos puderam dar mais sentido e significado aos conteúdos discutidos nessas salas.

Portanto, o conceito de CoP nos proporcionou compreender a "aprendizagem como forma de participação" (Wenger, 2001). Nessas pesquisas, se observa que as professoras se envolviam com seu processo de aprendizagem, porque ao participarem de formação continuada com características de uma CoP. O que favoreceu que as docentes construíssem juntas um sentido e significado para suas experiências de ensinar e aprender números e operações.

\section{Referências}

ABRAHÃO, A. M. C. Frações e Decimais: compreender para ensinar números racionais. Perspectivas da Educação Matemática. Mato Grosso do Sul. Vol. 9, n. 21, p.680 - 701, 2016.

ABRAHÃO, A. M. C.; NAMAN, L.; SPINOLA, M. da S. Pesquisas sobre a formação matemática para a docência no início da escolarização. In: SEMINÁRIO DE PESQUISA EM EDUCAÇÃO MATEMÁTICA, 7, 2017, Rio de Janeiro. Anais do VIII Seminário de Pesquisa em Educação Matemática. Rio de Janeiro: SBEMRJ, 2017. p. 12- 26.

BAZET, L. M. B.; Aprendizagens docentes em grupo de estudos sobre divisão: narrativas de práticas pedagógicas com crianças. 2014. 114 f. Dissertação (Mestrado Profissional em Educação em Ciências e Matemática). Instituto Federal do Espírito Santo, Espírito Santo, 2014.

COSTA, J. M.; PINHEIRO, N. A. M.; COSTA, É. A formação para matemática do professor de anos iniciais. Ciências da Educação, Bauru, v.22, n.2, p.505-522, 2016.

CURI, E.; PIRES, C. M. C. Pesquisas sobre a formação do professor que ensina matemática por grupos de pesquisa de instituições paulistanas. Educação Matemática Pesquisa, 10 (1), 151189, São Paulo, 2008.

FIORENTINI, D.; PASSOS, C. L. B.; LIMA, R. C. R. de. Mapeamento da pesquisa acadêmica brasileira sobre o professor que ensina matemática: período 2001 - 2012. Campinas, SP: FE/UNICAMP, 2016.

FREIRE, M. Avaliação e Planejamento. A prática educativa em questão. Instrumentos metodológicos II. 1ạ ed. São Paulo: Espaço Pedagógico, 1997.

GAIGHER, V. R. Formação do Professor de Matemática em alunas de resolução de problemas a partir de ações colaborativas e reflexivas. 2017. 157 f. Dissertação (Mestrado Profissional em 
Educação em Ciências e Matemática). Instituto do Espírito Santo, 2017.

GATTI, B. A; BARRETO, E. S. de. Professores do Brasil: impasses e desafios. 1a ed.. Brasília: UNESCO, 2009.

LAVE, J.; WENGER, E. Situated Learning: Legitimate Peripheral Participation. New York: Cambridge University Press, 1991.

LOPES, A. F. Formação de professores dos anos iniciais sobre o processo de ensino e aprendizagem de frações. In: EDUCAÇÃO MATEMÁTICA NA CONTEMPORANEIDADE: DESAFIOS E POSSIBILIDADES, 12, 2016, São Paulo. Anais Encontro Nacional de Educação Matemática, São Paulo: SBEM, 2016. p. 1-12.

LOPES, A. F. CÔCO, D.; SILVA, S. A. F. Formação continuada de professores e estudos sobre o significado de frações parte-todo. In: CONGRESSO INTERNACIONAL DE ENSINO DA MATEMÁTICA, 7, 2017, Canoas. Anais do Congresso Internacional de Ensino da Matemática. Canoas: ULBRA, 2017, p. 1-11.

OLIVEIRA, A. T. de C. C. de; ABRAHÃO, A. M. C.; PAIVA, M. A. V.; SILVA, S. A. F. da. Mapeamento da pesquisa fluminense e capixaba sobre o professor que ensina matemática: principais tendências temáticas. In: FIORENTINI, D.; PASSOS, C. L. B.; LIMA, R. C. R. de. Mapeamento da pesquisa acadêmica brasileira sobre o professor que ensina matemática: período 2001 - 2012. Campinas, SP: FE/UNICAMP, 2016.

SESSA, S. de M. A constituição de um grupo de estudos de professores que ensinam matemática e suas repercussões no contexto escolar. 2015. 124 f. Dissertação (Mestrado Profissional em Educação e Ciências e Matemática). Instituto Federal do Espírito Santo. Espírito Santo. 2014.

SILVA, S. A. F. da; CÔCO, D. Formação continuada de professores que ensinam matemática na infância: reflexões conceituais e práticas. Caderno de Pesquisa, São Luís, v. 24, n. Especial, set/dez, p. 68-88, 2017.

WENGER, E. Comunities of Practices: Learning. Meaning, and Identity. New York: Cambridge University Press, 1998.

WENGER, E. Comunidades de Práctica: Aprendizaje, significado e identidad. Barcelona: Paidós, 2001.

WENGER, E. Comunities of Practices. A brief introduction. 2015. Disponível em: http://wengertrayner.com/wp-content/uploads/2015/04/07-Brief-introduction-to-communities-ofpractice.pdf. Acesso em: 20 mar. 2016.

Recebido em maio de 2018.

Aprovado em maior de 2019. 